\title{
RESEARCH ON THE DILEMMA AND COUNTERMEASURES OF POPULATION IN NORTHEAST CHINA
}

\author{
Miao Jin \\ School of Labor and Economics, Capital University of Economics and Business, Beijing,China \\ DOI: 10.46609/IJSSER.2020.v05i08.015 URL: https://doi.org/10.46609/IJSSER.2020.v05i08.015
}

\begin{abstract}
In the context of the liberalization of the two-child policy, the population fertility rate in Northeast China still maintains an ultra-low level, which brings about problems such as declining birthrate, aging population, and labor loss. Population loss and economic recession form a vicious circle. Using data from the National Bureau of Statistics and the national census, this article analyzes the population plight of Northeast China from four aspects: policy factors, economic factors, social environmental factors, and international factors, and puts forward corresponding policy recommendations: retain and attract more excellent talent, and provide protection for women's re-employment, increase policy support in border areas, and drive economic revitalization through various developments, so as to better solve the population plight in Northeast China.
\end{abstract}

Keywords: population structure; Northeast China; countermeasure analysis

\section{Introduction}

Before the 1990s, Northeast China was an important old industrial base and an economic development area dominated by natural resource extraction and commercial grain production. With the continuous deepening of reform and opening up and the adjustment of national development strategies, the Northeast region's economy has gradually declined. The proportion of the GDP of the three northeastern provinces in the country has dropped from $13.3 \%$ in 1978 to $6.2 \%$ in 2018, and the proportion has declined for six consecutive years. The outflow of population in the Northeast is a major factor in accelerating the economic recession. Since the 1980s, the Northeast has strictly implemented the family planning policy, and its population fertility rate has been declining. In the mid-1990s, Northeast China entered a period of ultra-low fertility levels. As an important social resource, human beings promote its social and economic development. However, in recent years, the population of Northeast China has experienced negative growth year after year. On the one hand, the population outflow is serious and the total 


\section{International Journal of Social Science and Economic Research}

ISSN: $2455-8834$

Volume:05, Issue:08 "August 2020"

population continues to decline. On the other hand, the low fertility rate reduces the proportion of children. As early as the sixth national census in 2010, it was found that the combined birth rates of Heilongjiang, Jilin and Liaoning were $0.751,0.760$, and 0.741 respectively, which were far lower than the national average of 1.181. The low total birth rate and large net population outflow have enabled the Northeast to enter an aging society ahead of schedule.

The "Report on the Development of China's Floating Population" published by the National Health and Family Planning Commission in 2016 described population changes in the Northeast. The birth rate in the Northeast is extremely low, and the population tends to stagnate. Severe aging, low willingness to give birth, and population exodus make the population in the Northeast face predicament, which hinders social and economic development. The Northeast region must grasp the fundamental causes and seek effective solutions to bring about effective changes to the local population's plight and economic development. Studying the population characteristics, structural characteristics, and willingness to bear children of the population migration in the Northeast can better understand and solve the population plight of the Northeast. In October 2003, the Central Committee of the Communist Party of China and the State Council issued the "Several Opinions on the Implementation of the Revitalization Strategy for Old Industrial Bases in Northeast China", which clarified the guiding ideology, principles, tasks, and policy measures for implementing the revitalization strategy. With the development of policies, the Northeast region has accelerated the pace of reform. However, in the past decade or so, the new measures to revitalize the old industries in the Northeast have not paid much attention to the population problem. The research of this article mainly conducts a preliminary analysis of the predicament of the population problem in the Northeast, and objectively reflects the current population problem in the Northeast.

\section{Population changes in Northeast China}

With the deepening of the socialist market economic system, the Northeast region's economy has gradually declined. The fundamental cause lies in the population problem. In 1982, the proportion of permanent residents aged 20-39 in the Northeast region began to decline. At the same time, the fertility rate continued to drop and the population showed a negative growth trend. . In addition, problems such as severe population exodus and poor willingness to give birth have also made the population aging in the Northeast region increasingly serious.

(1) Declining birthrate

The permanent population in Northeast China has experienced negative growth. Table 1 below is based on the data of the fifth census in 2000 and the sixth census in 2010. In the fifth census data, the total birth rate in Heilongjiang, Jilin and Liaoning were 0.88, 0.84, and 0.98, respectively, which was lower than the national average of 1.22 . In the sixth national census, the 


\section{International Journal of Social Science and Economic Research}

ISSN: $2455-8834$

Volume:05, Issue:08 "August 2020"

combined birth rates of Heilongjiang, Jilin and Liaoning were 0.75, 0.76, and 0.74, respectively, which were far lower than the national average of 1.18. In the sixth census, the average fertility rate in the three northeastern provinces was 0.75 , which is equivalent to 4 couples having 3 children, the lowest level in the country. It can be seen from Table 1 that the total birth rate of cities and towns in the fifth census in Northeast China is lower than that in the sixth census. However, the situation in the villages in Northeast China is slightly different. In the fifth census of Heilongjiang and Jilin provinces, the total birth rate in the villages was lower than that of the sixth census, but the opposite was true in Liaoning Province. The national total fertility rate ${ }^{1}$ has been maintained at a low level, and in 2010 it was as low as 1.18. It is generally believed that a country's population replacement level below 2.1 will result in a decrease in the country's total population. According to international standards, the total fertility rate below 1.3 is called "ultralow fertility rate." In parts of the Northeast, this situation has continued for more than 20 years. It can be seen that the total birth rate in Northeast China has continued to decline in recent years, which has had a greater impact on the number of births in my country, as shown in Table 2.

Table 1 The total birth rate of the fifth and sixth census

Province

\begin{tabular}{ccccc} 
& Heilongjiang Province & Jilin Province & Liaoning Province & Nationwide \\
\hline The Fifth Census & 0.88 & 0.84 & 0.98 & 1.22 \\
City & 0.73 & 0.70 & 0.76 & 0.86 \\
Town & 0.91 & 0.88 & 1.03 & 1.08 \\
Rural & 0.96 & 0.92 & 0.74 & 1.18 \\
The sixth census & 0.75 & 0.76 & 0.74 & 1.18 \\
City & 0.67 & 0.59 & 0.61 & 0.88 \\
Town & 0.70 & 0.74 & 0.70 & 1.15 \\
Rural & 0.85 & 0.90 & 0.96 & 1.44 \\
\hline
\end{tabular}

Source: Based on the data of the fifth and sixth census.

Table 2 is a table of the natural population growth rate in Northeast China and the whole country from 1978 to 2017 (\%). The natural population growth rate can reflect the rate of population development. It can be seen from Table 2 that during the period of reform and opening up in 1978, the natural population growth rate in Northeast China was higher than the national level. However, after the implementation of the family planning policy, the average natural population

\footnotetext{
${ }^{1}$ Total fertility rate: refers to the average number of children born to each woman during the childbearing age of a country or region. Generally speaking, if the total fertility rate is lower than 2.1 (for developed countries), the newborn population is not enough to make up for the number of birth women and their partners.
} 
International Journal of Social Science and Economic Research

ISSN: 2455-8834

Volume:05, Issue:08 "August 2020"

growth rate of Heilongjiang, Jilin, Liaoning and Northeast provinces in 1990 were 11.76\%, $12.50 \%$ o, 8.80\% , 11.02\%o, which were all lower than the national level of $14.39 \%$. Until 1990 , the natural population growth rate of the whole country and the three northeastern provinces showed a downward trend year after year. In 2017, the average natural population growth rate of Heilongjiang Province, Jilin Province, Liaoning Province and the three northeastern provinces were $-0.41 \%$, $0.26 \%$, $-7.8 \%$, and $-2.65 \%$, which were far lower than the national level of $5.32 \%$. In 2017, the natural population growth rate of Heilongjiang and Liaoning provinces was negative, indicating that the population of the two provinces is decreasing. On January 1, 2016, China fully liberalized the two-child policy. In 2017, the national birth population was only 17.23 million, and the birth rate was $12.43 \%$. In 2017 , the natural population growth rate of Jilin Province was at a low level, and the other two provinces had negative growth. It shows that the full liberalization of the two-child policy has not effectively alleviated the current population problem in Northeast China.

Table 2 The natural population growth rate of Northeast China and the whole country from 1978 to 2017 (\%)

\begin{tabular}{lccccc}
\hline Years & $\begin{array}{c}\text { Heilongjiang } \\
\text { Province }\end{array}$ & $\begin{array}{c}\text { Jilin } \\
\text { Province }\end{array}$ & $\begin{array}{c}\text { Liaoning } \\
\text { Province }\end{array}$ & $\begin{array}{c}\text { Average of the three } \\
\text { northeastern provinces }\end{array}$ & Nationwide \\
\hline 1978 & 12.16 & 13.90 & 12.70 & 12.92 & 12.00 \\
1981 & 8.24 & 12.40 & 11.30 & 10.65 & 14.55 \\
1984 & 9.77 & 6.50 & 5.80 & 7.36 & 13.98 \\
1987 & 14.00 & 9.90 & 12.00 & 11.97 & 16.61 \\
1990 & 11.76 & 12.50 & 8.80 & 11.02 & 14.39 \\
1993 & 10.38 & 7.80 & 4.40 & 7.53 & 11.45 \\
1996 & 7.35 & 6.90 & 3.70 & 5.98 & 10.42 \\
1999 & 5.06 & 5.20 & 2.00 & 4.09 & 8.18 \\
2002 & 2.54 & 3.20 & 2.10 & 2.61 & 6.45 \\
2005 & 2.67 & 2.60 & 1.20 & 2.16 & 5.89 \\
2008 & 2.23 & 1.60 & 1.10 & 1.64 & 5.08 \\
2011 & 1.27 & 1.02 & 0.30 & 0.86 & 4.79 \\
2014 & 0.91 & 0.40 & 1.90 & 1.07 & 5.21 \\
2017 & -0.41 & 0.26 & -7.80 & -2.65 & 5.32 \\
\hline
\end{tabular}

Source: Based on the statistical yearbooks of the whole country and the three northeastern provinces over the years.

(2) Population ageing

Table 3 shows the proportion (\%) of the total population aged 65 years and over in the fifth and sixth censuses (\%). From Table 3, it can be seen that the proportion of the total population 


\section{International Journal of Social Science and Economic Research}

ISSN: $2455-8834$

Volume:05, Issue:08 "August 2020"

aged 65 years and over in the fifth census is lower than the sixth census. The results of the second census. At the same time, the results of the two censuses showed that cities accounted for a higher proportion of the total population of 65 and over than in rural areas, indicating that the proportion of people aged 65 and over in cities is larger. In the Northeast, Liaoning Province has the most serious aging problem. In 2018, Liaoning Province's "Report on the Status of Elderly Population Information and Aging Career Development in Liaoning Province in 2017" released by Liaoning Province in 2018 showed that as of the end of 2017, Liaoning Province was 65 years of age and older. People accounted for $14.37 \%$ of the total population. According to the United Nations standard, a region with an elderly population of 65 years and over accounting for $7 \%$ of the total population is considered an aging society.

Table 3 Proportion of the total population aged 65 and above in the fifth and sixth census $(\%)$

Province

\begin{tabular}{ccccc} 
& Heilongjiang Province & Jilin Province & Liaoning Province & Nationwide \\
\hline The Fifth Census & 5.56 & 6.04 & 7.88 & 7.10 \\
City & 6.30 & 6.31 & 8.22 & 6.67 \\
Town & 5.51 & 5.88 & 6.86 & 5.99 \\
Rural & 5.04 & 5.91 & 7.80 & 7.50 \\
The sixth census & 9.40 & 9.05 & 10.31 & 8.92 \\
City & 9.40 & 9.05 & 10.50 & 7.68 \\
Town & 8.65 & 8.64 & 9.43 & 7.98 \\
Rural & 7.19 & 7.77 & 10.33 & 10.06 \\
\hline
\end{tabular}

Source: Based on the data of the fifth and sixth census.

Figure 1 shows the old-age dependency ratio of the Northeast region and the national average. It can be seen from Figure 1 that the national average and the old-age dependency ratio of the three northeastern provinces have shown an increasing trend year by year. Before 2002, the national old-age dependency ratio was higher than that of Northeast China, but the growth rate of the three Northeast provinces was higher than the national level. In 2003, the old-age dependency ratio in Liaoning Province was higher than the national average, reaching $12.84 \%$. However, from 2008 to 2010, the old-age dependency ratio in the three northeastern provinces showed a downward trend, but this downward trend remained relatively short, and then continued to show a fluctuating upward trend. From 2011 to 2017, the national average and the old-age dependency ratio in the Northeast showed a rapid upward trend, indicating that from an economic perspective, it reflects the serious aging of the population in the Northeast in recent years and the rapid increase in the proportion of the elderly population. 
International Journal of Social Science and Economic Research

ISSN: 2455-8834

Volume:05, Issue:08 "August 2020"

Figure 1 The old-age dependency ratio in Northeast China and the national average (\%)

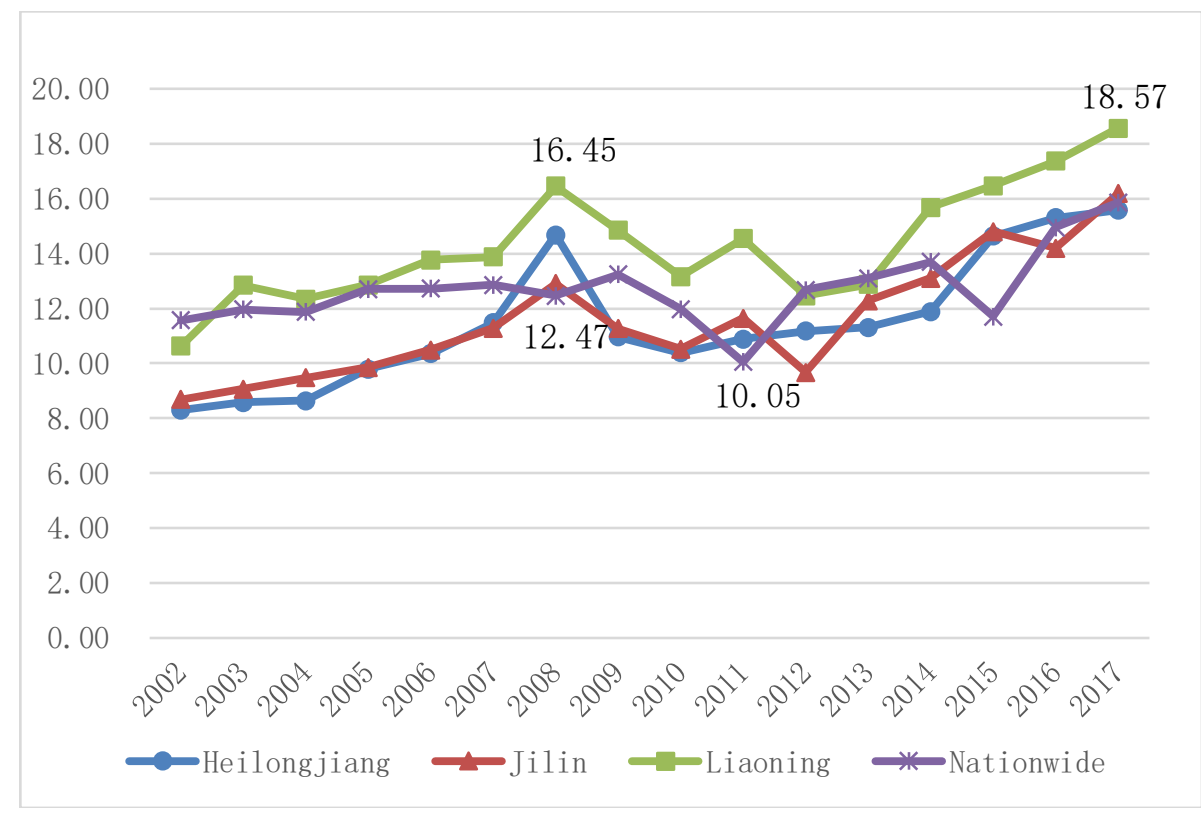

Source: Compiled by "China Population and Employment Statistical Yearbook" over the years.

(3) Loss of population and labor

In recent years, the competitiveness of the Northeast region has declined year by year, and the scale of net population migration has continued to increase. The market-oriented reforms in the Northeast region have had a great impact on the local industries. The demand for labor from the secondary industry is transformed into the tertiary industry. However, the development of the tertiary industry in the Northeast region is slow, so many laborers go out to work in the secondary industry. Or in the tertiary industry, leading to the outflow of population. At the same time, the student population is also a major factor in the population exodus, leading to a continuous decline in the proportion of young adults. There is also a new trend of population outflow in the Northeast, which is the elderly's old age. The Northeast is relatively northern, with higher latitudes, cold winters and longer time spans, especially for cardiovascular and cerebrovascular patients who prefer to spend the winter in the south. At the same time, many children of the elderly in the Northeast are working and living in the South, making the elderly in the Northeast travel between the two places all the year round, which has become a new trend of population exodus.

Table 4 shows the net out-of-province population migrants in Northeast China. It can be seen from Table 4 that the population of Heilongjiang and Jilin Provinces showed a state of net 
International Journal of Social Science and Economic Research

ISSN: 2455-8834

Volume:05, Issue:08 "August 2020"

migrants, and Heilongjiang Province in the Northeast has the most serious net migrants. In the fifth census in 2000 and the sixth census in 2010, the net emigration numbers were 787,000 and 2.047 million respectively, and the total net emigration in Heilongjiang Province is still high in the census-length data. However, in the northeastern region, Jilin Province has the highest net emigration rate among the three provinces. The data in the sixth census in 2010 was 3.1 times higher than the data in the fifth census in 2000. Unlike the other two provinces, Liaoning Province is the only province with a net migration. The number of people who migrated from 683,000 in 2000 to 773,000 in 2010 . On the whole, the net emigration volume of the entire Northeast region is relatively large.

Table 4 The number of net migration out of the province of the population in Northeast China (10,000 people)

\begin{tabular}{ccccc}
\hline & \multicolumn{2}{c}{ Census data } & \multicolumn{2}{c}{ Census length data } \\
\cline { 2 - 5 } Province & 2000 & 2010 & $1995-2000$ & $2005-2010$ \\
\hline Heilongjiang Province & 78.7 & 204.7 & 63.8 & 114.0 \\
Jilin Province & 30.0 & 91.6 & 27.5 & 50.9 \\
Liaoning Province & -68.3 & -77.3 & -37.6 & -49.5 \\
North-east area & 40.4 & 219.1 & 53.8 & 115.4 \\
\hline
\end{tabular}

Source: Compiled and calculated based on data compiled from China's fifth and sixth census.

Table 5 shows the number of people registered in other provinces by education level. According to the fifth and sixth census data, the proportion of people who graduated from junior high school and went out to work in Northeast China is relatively large, and the proportion is increasing year by year. In 2000, Heilongjiang, Jilin and Liaoning provinces accounted for $35.3 \%, 34.5 \%$ and $41.3 \%$ of the population of other provinces after graduating from junior high school. In 2010, Heilongjiang, Jilin and Liaoning provinces accounted for $43.7 \%$, 42.5\%, and $52.4 \%$ of the out-of-town population after graduating from junior high school. The proportions of elementary and university undergraduates are ranked second and third respectively. It is worth noting that the proportion of undergraduates in the population of other provinces has increased, indicating that the brain drain phenomenon of the three northeastern provinces is more serious. 
International Journal of Social Science and Economic Research

ISSN: 2455-8834

Volume:05, Issue:08 "August 2020"

Table 5 Population with registered permanent residence in other provinces by education level (\%)

\begin{tabular}{ccccccc}
\hline \multirow{2}{*}{ education level } & \multicolumn{3}{c}{ The Fifth Census } & \multicolumn{3}{c}{ The sixth census } \\
\cline { 2 - 7 } & $\begin{array}{c}\text { Heilongjiang } \\
\text { Province }\end{array}$ & $\begin{array}{c}\text { Jilin } \\
\text { Province }\end{array}$ & $\begin{array}{c}\text { Liaoning } \\
\text { Province }\end{array}$ & $\begin{array}{c}\text { Heilongjiang } \\
\text { Province }\end{array}$ & $\begin{array}{c}\text { Jilin } \\
\text { Province }\end{array}$ & $\begin{array}{c}\text { Liaoning } \\
\text { Province }\end{array}$ \\
\hline Never attended school & 6.45 & 4.61 & 4.2 & 2.24 & 1.6 & 1.34 \\
Literacy class & 0.37 & 0.42 & 0.17 & - & - & - \\
Primary school & 25.79 & 22.59 & 27.31 & 18.37 & 15.99 & 19.45 \\
Junior high school & 35.34 & 34.52 & 41.32 & 43.69 & 42.51 & 52.37 \\
High school & 7.61 & 7.45 & 8.31 & 12.32 & 13.12 & 12.53 \\
Technical secondary school & 3.25 & 4.37 & 3.49 & - & - & - \\
College & 4.58 & 6.36 & 4.48 & 7.67 & 6.52 & 5.76 \\
Undergraduate & 15.98 & 18.68 & 10.06 & 14.91 & 19.08 & 7.85 \\
Postgraduate & 0.63 & 0.98 & 0.65 & 0.8 & 1.18 & 0.7 \\
Total & 100.00 & 100.00 & 100.00 & 100.00 & 100.00 & 100.00 \\
\hline
\end{tabular}

Source: Compiled and calculated based on data compiled from China's fifth and sixth census.

\section{Factors influencing the population dilemma in Northeast}

\section{(1) Policy factors}

Since the beginning of the founding of the People's Republic of China, the Northeast region has been an important industrial base and grain production area in my country, and its economy has developed rapidly. In 1978, my country implemented reform and opening up, and the northeast region was bound by the traditional industrial structure and geographic region, and the economic development was slower than the eastern coastal region. Family planning was established as a basic national policy in September 1982, and it was written into the constitution in December of the same year. The Northeast has high urbanization and many state-owned enterprises, so the family planning policy in the Northeast has been implemented well, resulting in a decline in the birth rate and natural population growth rate in the Northeast. After the reform and opening up, my country's eastern coastal areas benefited from their advantageous geographical location and the support of national policies, and a large number of young people in the northeast went out to work. On November 14, 1993, the "Decision of the Central Committee of the Communist Party of China on Several Issues Concerning the Establishment of a Socialist Market Economic System" put forward several major issues regarding the establishment of a socialist market economic system. In 1997, the 15th National Congress of the Communist Party of China officially proposed to adjust the layout of the state-owned economy strategically. At the end of the 20th century, a large number of state-owned workers were laid off in the northeast region, 


\section{International Journal of Social Science and Economic Research}

ISSN: $2455-8834$

Volume:05, Issue:08 "August 2020"

and the number of people who went out to work continued to increase.

\section{(2) Economic factors}

At this stage, the population structure of the Northeast region presents an inverted triangle shape, and the aging of the population continues to deepen. At the same time, the economy of the Northeast region began to decelerate. In 1978, the economic growth rates of Heilongjiang, Jilin and Liaoning were $11.1 \%, 12.8 \%$, and $10.7 \%$, respectively. In 2018, the economic growth rates of Heilongjiang, Jilin and Liaoning were $4.7 \%, 4.5 \%, 5.7 \%$. The economic growth rate fluctuated greatly in the past four decades. It is worth noting that the economic growth rate of Liaoning Province in 2016 was negative for the first time, at $-2.5 \%$. Under the double blow of the population exodus and the high total birth rate, the total population of the Northeast has been declining year by year. Data from the sixth census in 2010 showed that children aged 0-14 accounted for $16.6 \%$ of the total population, while the proportion of Northeast China was only $11.8 \%$, indicating that the Northeast will show a shortage of labor resources in the future, which will also lead to the Northeast. The aging of the population is increasing. At the same time, young people in the Northeast have low desire for childbirth and low consumption desire among the elderly, which further leads to economic depression and exacerbates population loss.

\section{(3) Social environmental factors}

The urbanization rate in Northeast China has always been high, but the fertility rate and the urbanization rate often show an inversely proportional trend, that is, the higher the urbanization rate, the lower the fertility rate. According to my country's sixth population census in 2010, the illiteracy rate in Northeast China is very low. According to the ranking from low to high, Jilin Province ranks second in the country, Liaoning Province third, and Heilongjiang Province fifth. In recent years, school district housing, education expenditures, daily expenses and other expenses have increased the cost of childcare, which has also increased the financial pressure on a family. The Northeast region is an "immigrant society", so the traditional concepts of raising children and guarding against the elderly, patriarchal thinking, etc. are weak, so the willingness to bear children is low. The Ministry of Civil Affairs released the social service statistics of all provinces in 2018. The results showed that Heilongjiang, Jilin and Liaoning were the first, third, and fourth in the country with $63 \%, 62 \%$, and $54 \%$ respectively. The high rate of divorce ${ }^{2}$ and unstable marital status will also lead to lower willingness to have children, which will affect the demographic structure.

\footnotetext{
${ }^{2}$ The separation ratio refers to the ratio of the number of divorces to the number of marriages in a certain period (usually a year), usually expressed as a percentage.
} 


\section{International Journal of Social Science and Economic Research}

ISSN: $2455-8834$

Volume:05, Issue:08 "August 2020"

(4) International factors

Northeast China is a border area of China, adjacent to Russia, Mongolia and North Korea. In 2017, the combined birth rates of Russia, Mongolia and North Korea were 1.76, 2.71, 1.91, respectively. And the birth rate is 1.76 , which is far below the international level, and the population of Russia mainly migrates to the more developed cities such as Moscow. The economic development level of the Far East is relatively poor, which has a small contribution to the economic development of the Northeast. North Korea is a developing country with a low total fertility rate. Therefore, the population situation of neighboring countries is not conducive to the population development of Northeast China. The Northeast is a multi-ethnic region, mainly Han, Korean, Manchu, Mongolian, etc. The slow economic development in the Northeast has caused many laborers to go out to work, and some of them choose to work abroad. The number of Korean workers going to South Korea in the Northeast region is relatively large. Due to the higher income of working in South Korea and the advantages of the Korean language, going to South Korea is very smooth, so the loss of the Korean population in the Northeast is more serious. In addition, South Korea has introduced a policy that Koreans can go to work and live in South Korea after graduation. Therefore, South Korea has attracted some Koreans with a university degree or above to work and live in South Korea, which has led to the loss of the minority population.

\section{Countermeasures and suggestions}

(1) Retain and attract more outstanding talents

Talents are the first resource for innovation and development. In recent years, all provinces across the country have been formulating and implementing guidelines and policies to attract talents, such as the educational settlement system, preferential house purchase, and child placement. Due to geographical constraints, talents from other provinces hope to go to cities with relatively convenient geographical locations. Therefore, to ensure that the Northeast region can retain and attract talents, it must be able to meet the expectations of talents for future development and the needs of material life. First of all, it is very important to be able to retain talents in the northeastern region. Only locals can find better jobs and salary positions in their hometowns, and they don't want to leave their homes and go alone. In addition, on the basis of retaining local talents, as much as possible, attract more talents from other provinces and foreign countries to stay in the Northeast, exchange with each other, and jointly revitalize the economy of the Northeast. Retaining and attracting more outstanding talents can also allow them to stay in the Northeast for development and take root and settle down, so as to better solve the population problem in the Northeast at this stage. 


\section{International Journal of Social Science and Economic Research}

ISSN: $2455-8834$

Volume:05, Issue:08 "August 2020"

(2) Provide protection for women's re-employment and re-employment

Most women in our country reluctantly quit suitable jobs when they get married and have children. However, due to the increase in the burden of childcare, many women hope that through reemployment, they can subsidize their families and enrich their lives. However, in the process of reemployment, women will face the "invisible threshold" when recruiting units are unwilling to hire women with relatively small children. The Ministry of Human Resources and Social Security and other nine departments issued the "Notice on Further Regulating Recruitment Behavior and Promoting Women's Employment" to protect employees' right to parental leave in legal form, but they did not have a good policy to help reemployed women. In this regard, the Northeast region should learn from Japan's successful experience, take the lead by large companies, and establish company re-employment training and guidance. Employees who perform well in training can stay in the company. And actively call on private enterprises to carry out kindergarten business to reduce the number of "standby children", and well achieve the goal of all "standby children" enrolling in nursery schools, so that parents can devote themselves to work. This practice in Japan has made efforts to reduce the number of "standby children" in various regions, thereby improving the problem of leaving children unattended without giving birth, which affects the birth rate.

\section{(3) Increase policy support in border areas}

As the Northeast is part of my country's border zone, neighboring three countries, the latitude is relatively high, and the winter time is long and cold, so the population of the border area shows a trend of decreasing year by year. The geographical location of border areas is limited, and the construction or upgrading of railways and highways in border areas needs to be accelerated to facilitate people's travel. The three neighboring countries in the Northeast are the Far East of Russia, North Korea, and Mongolia. The economic development of these three countries is relatively slow, so the people in the border areas have poor foreign trade and economic development. The state should give more preferential policies and financial support to border areas in terms of foreign cooperation. At the same time, appropriate construction projects should be tilted to the border areas to provide support for the development of the border areas, so as to better retain and attract people in the border areas, so as to better solve the population problem of the northeast border.

(4) Multi-faceted development drives economic revitalization

The Northeast region is an important old industrial base in my country, but the economic development has been lagging behind in recent years, which has brought about a series of problems, such as insufficient labor supply, poor consumption capacity, and low investment 


\section{International Journal of Social Science and Economic Research}

ISSN: $2455-8834$

Volume:05, Issue:08 "August 2020"

levels. The population structure and economic development are complementary to each other. In order to effectively solve the population dilemma in the Northeast, the Northeast should form a virtuous circle of economic development and population agglomeration, focusing on the development of the tertiary industry, attracting more people to invest, and creating more More jobs. The government should also draw on the successful experience of foreign transitions, and formulate corresponding fiscal policies, employment policies, and social security systems. Coordinate the relationship between the market and the government, work hard to do a good job in social security, infrastructure construction, education and other aspects of people's livelihood, and restore the economy of the Northeast, so as to better fundamentally solve the population problem facing the Northeast at this stage.

\section{Summary}

In recent years, my country's northeast region has faced problems such as economic recession and slow population growth. Today, with the full implementation of the two-child policy, the Northeast region still faces problems such as declining birthrate, aging population, and labor loss. The low total fertility rate in the Northeast has led to a negative growth trend of the population under low fertility levels. At the same time, the Northeast is an "immigrant society", and has a weak sense of traditional concepts such as having more children, raising children and preventing the elderly. Due to the high cost of childcare and living burden at this stage, the willingness of young people to have children in the Northeast continues to decline. The continued decline in the fertility rate in the Northeast will result in insufficient labor force reserve resources and the aging of the population will increase. The loss of labor force in Northeast China is serious. The population of Heilongjiang Province and Jilin Province are showing a state of net emigration, and in terms of total net emigration, Heilongjiang Province is the most serious. At the same time, the proportion of high-educated groups among the migrant groups has shown an upward trend. Facing the population dilemma in the Northeast, we put forward corresponding policy recommendations, formulating policies that can retain and attract more outstanding talents, provide protection for women's re-employment and re-employment, increase policy support in border areas, and drive the economy in various aspects Only by rejuvenating and proposing effective solutions from multiple perspectives can we effectively solve the predicament faced by the population in the Northeast.

\section{References}

[1] Han Meilan, Wu Xiling. Research on population problems and countermeasures in Northeast China under the new normal [J]. Journal of Yanbian University (Social Science Edition), 2018 (2018 01): 110-118. 
[2] Li Yutong, Zhang Jianyu. Looking at the population aging in Northeast China from the change of dependency ratio[J]. Journal of Demography, 2010, 6: 38-41.

[3] Hou Li, Yu Xiao. Outstanding population problems in Northeast China and their economic and social impacts[J]. Northeast Asia Forum, 2015 (5): 118-126.

[4] Yang Dongliang. A Comparative Study on the Resident Willingness of the Inflow and Outflow Population in Northeast China[J]. Journal of Demography, 2016 (5): 34-44.

[5] Hou Li. Analysis on the Causes of the Long-term Low Fertility Level in Northeast China[J]. Journal of Demography, 2018 (2018 02): 96-104. 